\title{
Valoración multicéntrica sobre el efecto terapéutico suplementario de los polipéptidos linforeticulares derivados del porcino en el curso clínico de diversas patologías
}

Multicenter evaluation of the supplementary therapeutic effect of porcine-derived lymphoreticular polypeptides in the clinical course of various pathologies

Valoração multicêntrica sobre o efeito terapêutico suplementario dos polipeptidos linfo reticulares derivados do porcino no curso clínico de diversas patologias.

\section{Víctor M. Acero Plazas, DMV Rosa Isabel Higuera Piedrahita, DMV, $\mathrm{MSc}_{3}$ Guillermo Mejía Mejía (Q.E.P.D), MD, Esp 4}

Recibido: 29 de agosto de 2019 Aprobado: 27 de noviembre de 2019

Publicado: 13 de enero de 2020

Cómo citar este artículo: Acero-Plazas VM, Higuera-Piedrahita RI, Mejía-Mejía G. Valoración multicéntrica sobre el efecto terapéutico suplementario de los polipéptidos linforeticulares derivados del porcino en el curso clínico de diversas patologías. Spei Domus. 2019;15(30-31): 1-22. doi: https://doi.org/10.16925/2382-4247.2020.01.01

Artículo de investigación. https://doi.org/10.16925/2382-4247.2020.01.01

1 Asociación Nacional de Médicos Veterinarios de Colombia (AMEVEC). Calle 101 No. 71A-52, Bogotá, Colombia. Tel: (57) 3214886347.

Correo electrónico: sepulvic@hotmail.com

2 Fundación Universitaria Agraria de Colombia (Uniagraria).

3 Universidad Nacional Autónoma de México (Cuautitlán Izcalli, México).

4 Laboratorios Urbimed S.A.S. 
2 Valoración multicéntrica sobre el efecto terapéutico suplementario de los polipéptidos linforeticulares derivados del porcino en el curso clínico de diversas patologías

\title{
Resumen
}

Introducción: los polipéptidos linforeticulares de origen esplénico y hepático porcino han sido postulados como agentes inmunomoduladores en humanos y una alternativa como coadyuvantes en tratamientos contra el cáncer y otras patologías. El objetivo de este estudio fue cuantificar mediante una encuesta dirigida a individuos especializados sobre el uso de los polipéptidos linforeticulares de origen porcino, como tratamiento y coadyuvante en diversas patologías.

Metodología: 136 médicos y profesionales de la salud, de alta calificación ético-profesional, ubicados en trece ciudades de Colombia, participaron en un estudio multicéntrico, retrospectivo, valorativo, basado en una encuesta sustentada en una escala de Likert (rango 1-9) en la que se pretende valorar el "efecto terapéutico suplementario" de los polipéptidos linforeticulares (low molecular weight -L.M.W-), desarrollados en este país y observados en el curso clínico de múltiples patologías, así como la aceptación de estos nuevos compuestos en la práctica médica corriente.

Resultados: se reportaron un total de 6.510 pacientes vistos y tratados durante un periodo comprendido entre los seis meses anteriores o más de tres años, en una revisión de casuística. Los resultados demuestran un interés general de todos los segmentos y disciplinas de la medicina por estos compuestos orgánicos y reconocen su utilidad en la práctica médica holística y ortodoxa. El $100 \%$ de los investigadores asociados valoraron el efecto terapéutico de estos péptidos específicos, y los clasificaron con valores entre 7 y 9 , es decir; (7) como bueno $(33,8 \%)$, (8) entre bueno y excelente $(34,5 \%$ ) y (9) como excelente $(26,4 \%)$, reportaron también algunos casos excepcionales.

Conclusiones: con base en los resultados se sugiere el uso de estos péptidos como coadyuvantes en el tratamiento de diversas patologías humanas.

Palabras clave: escala de Likert, inmunomoduladores, polipéptidos linforeticulares, porcino.

\begin{abstract}
Introduction: The limpho-reticular polypeptides from porcine source has been postulated as an alternative immunomodulator agents in humans, and coadyuvants in treatment of cancer and other pathologies. The objective of this study was to cuantify the use of this peptides as a regular treatment and coadyuvants in several pathologies.
\end{abstract}

Methods: One hundred and and thirty six (136) doctors in medicine and some others health professionals, previously qualified into a highly ethical and professional standards, placed in thirteen (13) Colombian cities, took part in a multicentrical, retrospective, valorative study , based in a Likert scale (Range1-9) that pretends to evaluate the "supplementary therapeutic effect" of some limpho-reticular polypeptides (Low Molecular Weight.-L.M.W.) developed in this country, observed during the clinical course of several pathologies, and also to know their attitude to allow for this innovative compounds in their regular medical practices.

Results: A total of 6.510 patients were reported to be seen, and treated during a period of time, between the late six months and more than three years backward, based in clinical records. The results shown an interest in all segments and disciplines of medicine, for this organic compound and recognize them to be of utility in their current medical practices, despite of their holistic or reductive tendencies. Hundred per cent (100\%) of the associate investigators valorate the supplementary therapeutic effects of this polypeptides, and reflex them into values between 7 and 9, meaning range (7) as good (33,8\%), (8) in a range between good - and excellent $(34,5 \%)$, and 9 as excellent $(26,4 \%)$, also reporting some outstanding cases.

Conclusions: Based on the results, the use of these peptides as adjuvants in the treatment of various human pathologies is suggested.

Keywords: Likert scale, immunomodulators, lyophoreticular polypeptides, porcine. 


\section{Resumo}

Introdução: os polipeptídios linfo reticulares de origem esplénico e hepático porcino foram postulados como agentes imuno modulador em humanos e uma alternativa como coadjuvante em tratamento contra o câncer e outras patologias. 0 objetivo deste estudo foi quantificar usando uma pesquisa dirigida a indivíduos especializados sobre o uso dos polipeptídios linfo reticulares de origem porcino como tratamento coadjuvante em diversas patologias.

Metodologia: 136 médicos e profissionais da saúde de alta qualificação ético profissional localizados em 13 cidades de Colômbia participaram num estudo multi centro, retrospectivo e valorativo, baseado numa pesquisa de perguntas na escala de Likert (1-9), na qual pretende valorar o "efeito terapêutico suplementario" dos polipeptídios linfo reticulares (low molecular weight -L.M.V.), desenvoltos neste país, observados no curso clínico de multiplas patologias, assim como aceitação de novos compostos na prática médica corrente.

Resultados: o estudo apresentou um total de 6.510 pacientes observados e tratados, no tempo de estudo compreendido entre os 6 meses anteriores ou mais de três anos numa revisão casuística. Os resultados apresentam um interesse geral de todos os segmentos e disciplinas da medicina por estes compostos orgânicos, e reconhecem sua utilidade na prática médica holística e ortodoxa. Os 100\% dos investigadores associados valoram o efeito terapéutico de peptídeos específicos e classificaram com valores de 7 à 9 , sendo bom (33.8\%), (34,5\%) bom -excelente e excelente $(26,4 \%)$, apresentando uns casos excepcionais.

Conclusões: Nos resultados observou-se que o uso de peptídeos como coadjuvantes no tratamento de diversas patologias humanas.

Palavras-chave: Escala de Likert, imunomoduladores, polipeptídeos lioforeticulares, suínos.

\section{Introducción}

A través de los años, el genoma del porcino ha sido utilizado para la selección de razas, cruces y productos de alta ingeniería genética. Esta capacidad de insertar material genético abrió grandes posibilidades y convirtió a los porcinos en animales esenciales en la investigación y medicina humana, en modelos para cirugía cardiovascular, coronaria, hígado, riñón, pulmón y útero. La posibilidad de obtener cerdos genéticamente modificados extendió la posibilidad de las investigaciones biomédicas orientadas a imitar enfermedades humanas para establecer protocolos de tratamiento adecuados, debido también a la semejanza en el genoma de las dos especies. E uso de órganos para xenotransplantes en humanos y para la producción de fármacos y otras alternativas terapéuticas sigue siendo explorado. Desde el punto de vista productivo agrícola, la demanda mundial de carne aumenta cada año a medida que la población y los ingresos crecen. Los porcinos mejorados y seleccionados genéticamente tienen el potencial de satisfacer esta demanda y permiten el desarrollo de líneas de mayor producción, alimentación, reproducción más eficiente y protección contra las enfermedades. Algunas de las aplicaciones biomédicas que se deben a los porcinos son: marcadores celulares (proteínas fluorescentes), xenotransplantes, 
4 Valoración multicéntrica sobre el efecto terapéutico suplementario de los polipéptidos linforeticulares derivados del porcino en el curso clínico de diversas patologías

desarrollos en enfermedades cardiovasculares, fibrosis quística, Alzheimer, diabetes, atrofia muscular espinal, hemofilia (proteínas recombinantes en la leche de la cerda), entre otros [1].

Así mismo, los porcinos son considerados un excelente modelo para el estudio de enfermedades infecciosas, donde estos animales resultan mucho mejores en cuanto a resultados comparados con los roedores de laboratorio. Algunos ejemplos de estos estudios se han centrado en Staphylococcus aureus (incluyendo cepas meticilino resistentes), pseudorabia, Alfaherpesvirus, Bordetella pertussis, virus de la influenza $\left(\mathrm{H}_{1} \mathrm{~N}_{1}, \mathrm{H}_{1} \mathrm{~N}_{2}, \mathrm{H}_{3} \mathrm{~N}_{2}\right)$, Mycobacterium tuberculosis, Pseudomonas aeruginosa. Algunas de las ventajas de los porcinos frente a otras especies son las siguientes: amplia disponibilidad de la especies, tamaño (algunas razas pequeñas), posibilidad de realizar diversos procedimientos quirúrgicos y recolección de muestras, omnívoro, longevidad, madurez sexual temprana, gestación de mediana duración, reproducción no estacional, tamaño de la camada amplio, condiciones de reproducción estandarizadas, homología con el genoma humano, comparten cerca del 80 \% de parámetros inmunes junto con los humanos, mientras que un roedor es del $10 \%$, herramientas de laboratorio disponibles (líneas celulares, test de ELISA, microarrays), clonación, transgénesis, bioéticamente es más susceptible de ser utilizado en mayor medida que los primates [2].

En Oldenburgo, Alemania, hace algunos años, se implementaron los polipéptidos esplénicos de origen porcino (compuestos SP1-Polyerga®), introducidos en la farmacopea alemana y posicionados en Europa y China como terapia coadyuvante o alternativa para el tratamiento del cáncer [3-18]; esto motivó, desde hace más de tres décadas, a un grupo multidisciplinario de investigadores colombianos independientes (C\&D Pharma GMBH) en Bogotá, Colombia, a desarrollar desde 2001, los polipéptidos linforeticulares de bajo peso molecular (L.M.W.), obtenidos de células hepáticas y esplénicas porcinas, con diferentes ensayos y evidencias en humanos y animales [19-27], producto que actualmente se encuentra registrado en el mercado farmacéutico Colombiano (Uprone®, Uprokids $\AA$ ).

El trabajo científico relacionado y el producto desarrollado han sido presentados desde hace varios años en forma gradual y amplia, con exclusividad al honorable cuerpo médico colombiano y ante algunas autoridades académicas y científicas de Alemania, México, Perú y Estados Unidos. Los polipéptidos linforeticulares objeto de este estudio, al igual que sus afines, se posicionan científicamente como: reactantes de fase aguda (APR) y/o modificadores de la respuesta biológica (BRM) y se postulan como coadyuvantes metabólicos específicos, para su administración suplementaria en todos aquellos casos, en donde los procesos metabólicos se encuentran alterados 
y las defensas orgánicas disminuidas. Estos compuestos contienen un porcentaje de inmunoglobulinas activas en el sistema digestivo, aminoácidos, fracciones proteicas de bajo peso molecular, oligoelementos y vitamina $\mathrm{C}$, propios de las células hepáticas y esplénicas (sistema linfoide y reticuloendotelial porcino) y se espera que actúen de la misma manera que lo hacen los reactantes orgánicos de fase aguda, presentes en la última etapa de la respuesta inmune primaria [24].

Desde un principio, las regulaciones de la OMS, la FDA y los entes estatales locales, por razones no bien definidas, en muchas ocasiones, restringen o marginan la información, tanto a médicos como a usuarios, sobre los posibles o reales efectos suplementarios, indicaciones, propiedades y usos de estos compuestos orgánicos, esto desestimula la prescripción y el consumo, lo cual, en muchas ocasiones, no muestra el real efecto benéfico y terapéutico inherente [28]. En Colombia, este tipo de productos está catalogado como un "suplemento dietario, no un medicamento y que no suple los requerimientos de una dieta balanceada" [29 p1]. Uno de los problemas que se plantea es que todavía parece no estar muy claro qué significa específicamente ser, un "suplemento dietario" de estas características y cómo debe manejarse. Por otra parte, estos productos se encuentran para venta libre universalmente, lo cual podría propiciar el voz a voz y la autoprescripción indiscriminada.

El término suplemento dietario (dietary supplement) en países de habla hispana, podría inducir a una confusión ya que empezando es un desafortunado anglicismo, la palabra puede relacionarse con la dieta o dietético, por lo cual los pacientes suelen asociarlos con las dietas o como un aporte adicional de nutrientes. Los productos denominados "suplementos dietarios" son comúnmente utilizados por adultos en muchas partes del mundo, con evidencias que indican un aumento en el uso entre los años 80 y mediados de la década del 2000. Muchas veces son utilizados con la intención de mejorar o mantener la salud; de 2007 a 2010, en EE. UU., se estimó que solo el 23 \% de todos los suplementos se utilizaban según la recomendación de personal médico; por otro lado, su uso puede estar motivado, en parte, por la evidencia que sugiere que, al aumentar la ingesta de algunos componentes en la dieta, puede existir una disminución del riesgo para cáncer y enfermedades cardiovasculares [30].

El posible efecto terapéutico adicional de inmunoglobulinas activas por la vía oral, de fracciones proteicas con efectos terapéuticos específicos y actividad metabólica reconocida y la especificidad de los aminoácidos, es aún poco conocido, menos aún, por los pacientes potenciales usuarios de estos suplementos. No obstante, el Ministerio de Salud y Protección Social en 2005 reconoció a los suplementos dietarios como "aquellos productos que sin satisfacer o reunir los requisitos establecidos para ser alimento convencional, medicamento, producto fitoterapéutico o preparación a 
Valoración multicéntrica sobre el efecto terapéutico suplementario de los polipéptidos linforeticulares derivados del porcino en el curso clínico de diversas patologías

base de recursos naturales o bebidas alcohólicas, aporta elementos o compuestos que pueden ser coadyuvantes al mantenimiento de los procesos metabólicos del organismo" [29 p1]. Aun así, no se permite todavía denominarlos coadyuvantes metabólicos puntuales inmunomoduladores o modificadores de la respuesta biológica, o relacionarlos claramente con la acepción que la palabra "suplemento", la cual se define como: "algo que sirve para suplir, completar, aumentar o reforzar algo, añadir o reemplazar" [31]. Es decir, la información que se divulga de estos compuestos se ha dirigido más al concepto "ambiguo" de lo dietario, que a las acciones o efectos "suplementarios" de estos productos. Afortunadamente, en el reciente proyecto de publicidad, competencia de la SMPB (subdirección de medicamentos y productos biológicos) INVIMA (2011), parece existir consciencia de "estatus" para estos productos orgánicos y un interés por su mejor direccionamiento [32].

En Norteamérica, el descubridor de los factores quimiotácticos de transferencia (transfer factors) fue el doctor $\mathrm{H}$. Sherwood Lawrence, con resultados reportados de las experiencias con estos factores [33-35]. En Italia, la Dra. Rita Levi Montalcini (nobel de medicina en 1986), por sus estudios sobre los factores de crecimiento (growth factors) y sus efectos sobre las células nerviosas [36-38]. Durante las últimas tres décadas, se han estudiado y desarrollado en otros países algunos compuestos naturales de origen proteico, con propiedades terapéuticas útiles, los cuales se encuentran también categorizados en la industria farmacéutica como suplementos dietarios (dietary supplements), como es el caso de los péptidos obtenidos del calostro bovino (transfer factors) [39] y los oligopéptidos esplénicos porcinos (Polyerga Plus @) [9-22] y otros productos orgánicos de origen bovino o aviar (embrionarios, tímicos, hipofisiarios y pancreáticos), desarrollados y comercializados en Norteamérica, Asia y Europa [39-40].

El objetivo del presente estudio fue valorar el "efecto terapéutico suplementario" de estos compuestos y el grado de aceptación percibido por un grupo de médicos y profesionales colombianos.

\section{Materiales y métodos}

Se seleccionaron 150 médicos y profesionales de la salud, quienes utilizaban hace más de tres años el suplemento dietario a base de polipéptidos linforeticulares, en trece ciudades o localidades diferentes de Colombia, además, en su momento estaban en el ejercicio pleno de su actividad en sus diferentes centros de atención. A ellos se les invitó a participar en el estudio, en forma voluntaria y sin ningún compromiso económico ni jurídico. 
El principio activo que se valoró consistió en polipéptidos linforeticulares (L.M.W.) en sus presentaciones de cápsulas por 150 y 200 mg y granulado (sobres por 100 mg). Los participantes fueron previamente seleccionados según los siguientes criterios de inclusión:

1. Profesionales de quienes se tenía conocimiento de haber tenido experiencia previa en la formulación y uso de polipéptidos linforeticulares, objeto de estudio de este trabajo, durante mínimo cinco años.

2. Profesionales con grado universitario en medicina, nutrición y dietética, fisioterapia o enfermería, no se discriminaron las especialidades o disciplinas practicadas.

Criterios de exclusión:

1. Personas que no eran profesionales.

2. Profesionales que no tenían conocimiento ni experiencia en el manejo de la formulación o uso de polipéptidos linforeticulares.

La evaluación se llevó a cabo en los diferentes lugares de trabajo de los observadores, y estuvo constituida en una encuesta de valoración multicéntrica. Cada uno de los participantes firmó el compromiso de adherencia y se comprometió a responder el protocolo de ocho preguntas, relacionadas con diferentes ítems. Las evaluaciones fueron enviadas por correo certificado y devueltas por el mismo medio, debidamente diligenciadas.

Las respuestas fueron consignadas en la encuesta y fue enviada de manera confidencial al grupo de investigadores, para su tabulación y valoración.

Las preguntas expresadas en la ficha técnica hacen relación a:

1. Certificación de la experiencia previa con el uso de polipéptidos linforeticulares, requisito para adherir al estudio valorativo, retrospectivo, basado en la evidencia.

2. Dosis, posologías y presentaciones utilizadas.

3. Tiempo de conocimiento del producto.

4. Efectos colaterales observados atribuidos al producto.

5. Patologías en donde se ha tenido experiencia clínica certificada.

6. Percepción sobre los péptidos linforeticulares como un aporte útil en terapéutica y en el ejercicio profesional. 
7. Valoración subjetiva en una escala de Likert (1-9), sobre el efecto terapéutico observado con este tipo de péptidos. La aplicación de la escala de Likert (rango 1-9), se propuso en este ítem, con el objeto de valorar la percepción cualitativa que tienen los evaluadores, sobre el "efecto terapéutico" observado durante la prescripción suplementaria de polipéptidos linforeticulares (L.M.W.).

8. Relación de algún caso que el observador haya considerado como una respuesta clínica excepcional.

Se enviaron 150 cuestionarios a trece ciudades del país, los 150 evaluadores aceptaron su adherencia (100\%). se adhirieron también al estudio, de manera espontánea, un profesional de Cali y otro de Pereira. Otro profesional aportó su casuística y valoración, pero se rehusó a avalarla con datos, por lo cual la información fue descartada para análisis.

Para el efecto de la evaluación se aplicó una escala de Likert (Rango 1-9). La escala de Likert o método de evaluaciones sumarias es una escala psicométrica comúnmente utilizada en cuestionarios y es una escala de uso en encuestas de investigación. Cuando se responde a un elemento de un cuestionario elaborado con la técnica de Likert, se realiza especificando el nivel o puntaje al manifestar encontrarse de acuerdo o en desacuerdo con una declaración (elemento, ítem o reactivo). Diversas fuentes demuestran que la información obtenida en escalas con 5, 7 y 10 niveles posibles de respuesta evidencian las mismas características de respuesta, respecto a la "media, varianza, asimetría y curtosis", después de aplicar transformaciones simples [41-43]. Los investigadores fueron informados e instruidos sobre las características y aplicación de esta escala en el protocolo acordado.

\section{Resultados}

\section{Evaluadores}

En el momento del corte para la recolección de datos, solo se pudo obtener información de 136 participantes, por lo tanto, tomaron parte activa en el estudio 136 evaluadores, representando el 90,66 \% de los convocados. El universo estuvo representado por diversas especialidades (tabla 1). La mayoría de los participantes por especialidad fueron de Villavicencio, Bogotá y Tunja. 
Tabla 1. Evaluadores por especialidad y disciplina, según la ciudad de residencia o labor

\begin{tabular}{|c|c|c|c|c|c|}
\hline Ciudad & Medicina general & Pediatras & Dietistas & Especialistas & Medicina holística \\
\hline Tunja & 15 & & 1 & & 5 \\
\hline Chiquinquirá & 2 & & & & \\
\hline Duitama & 12 & & 2 & 1 & 4 \\
\hline Sogamoso & 11 & & 3 & & 1 \\
\hline Medellín & 2 & & & & 4 \\
\hline Bogotá & 18 & 4 & 4 & 3 & 3 \\
\hline Yopal & 11 & & & & \\
\hline Cali & & & & 1 & \\
\hline Neiva & 2 & & & & \\
\hline Pereira & 1 & & & & \\
\hline Granada & 2 & & & & \\
\hline Paz de Ariporo & 1 & & & & \\
\hline Villavicencio & 20 & 2 & & & 1 \\
\hline
\end{tabular}

Fuente: elaboración propia

Del total de profesionales encuestados, el 71,3 \% correspondió a la medicina general que abarca médicos generales e internistas y en segundo lugar con $13 \%$ que correspondió a todos aquellos profesionales que se desempeñan en las áreas de la medicina alternativa, homeopatía, osteopatía, medicina bioenergética y medicina holística. El porcentaje de profesionales participante y la especialidad, se pueden evidenciar en la figura 1.

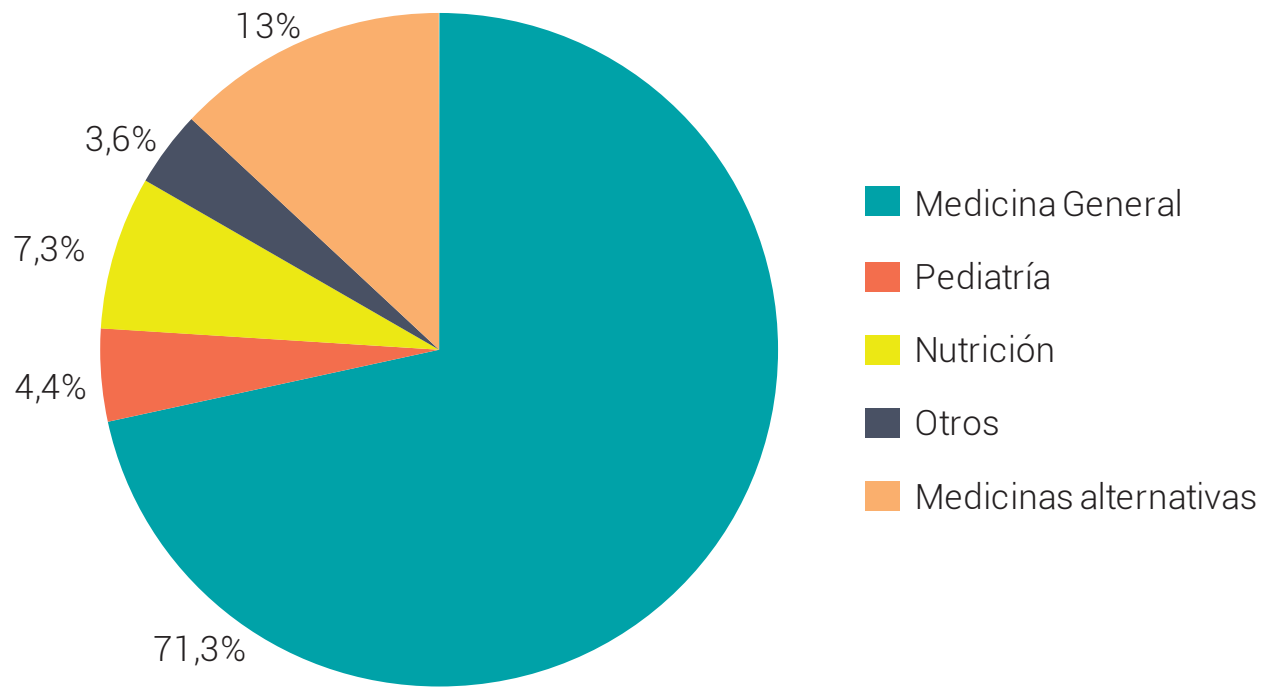

Figura 1. Especialidad de los profesionales participantes Fuente: elaboración propia 
Al recopilar el número de casos en los cuestionarios, la medicina holística, con un total de 17 profesionales encuestados, aporta un total de 1.955 casos, lo cual representa un $30 \%$ del total de casos reportados en las encuestas. Probablemente este tipo de profesionales, por la especialidad de la medicina que practican, incluyen este tipo de terapias en los tratamientos que realizan de manera rutinaria, por eso el alto número de casos.

\section{Origen de los encuestados}

Los participantes estaban ubicados en las siguientes ciudades del territorio colombiano: Bogotá, Medellín, Tunja, Chiquinquirá, Duitama, Sogamoso, Yopal, Villavicencio, Neiva, Pereira, Cali, Granada y Paz de Ariporo. Estas ciudades se escogieron según los lugares en los cuales el laboratorio tiene representación y en los cuales se confirmó que los profesionales tenían experiencia con el uso del producto. La ciudad que más evaluadores aportó estuvo representada por Bogotá (23,5\%), seguida de Villavicencio (16,9\%) y Tunja (15,4\%) (tabla 2$)$.

Tabla 2. Número y porcentaje de evaluadores por ciudades

\begin{tabular}{ccc}
\hline Ciudad & Total & \% \\
\hline Bogotá & 32 & 15,4 \\
\hline Villavicencio & 23 & 1,4 \\
\hline Tunja & 21 & 13,9 \\
\hline Duitama & 19 & 11,0 \\
\hline Sogamoso & 15 & 4,4 \\
\hline Yopal & 11 & 23,5 \\
\hline Medellín & 6 & 8,0 \\
\hline Chiquinquirá & 2 & 0,7 \\
\hline Neiva & 2 & 1,4 \\
\hline Granada & 2 & 0,7 \\
\hline Cali & 1 & 1,4 \\
\hline Paz de Ariporo & 1 & 0,7 \\
\hline Pereira & 1 & 16,9 \\
\hline & $\mathbf{1 3 6}$ & $\mathbf{1 0 0}$ \\
\hline
\end{tabular}

Fuente: elaboración propia 


\section{Número de pacientes evaluados}

Los participantes reportaron haber tratado con polipéptidos linforeticulares, entre todos los encuestados, un total de 6.510 pacientes, durante el tiempo transcurrido desde su primera experiencia con el uso de polipéptidos linforeticulares hasta el momento de realizar la encuesta. La ciudad que más casos aporta es Tunja (23,4 \%) seguida por Bogotá (22,0 \%) y Chiquinquirá (13,6\%) (tabla 3).

Tabla 3. Número de pacientes reportados por ciudad

\begin{tabular}{ccc}
\hline Ciudad & Casos & $\%$ \\
\hline Tunja & 1525 & 23,4 \\
\hline Bogotá & 1433 & 22,0 \\
\hline Chiquinquirá & 890 & 13,6 \\
\hline Duitama & 856 & 13,1 \\
\hline Sogamoso & 464 & 7,1 \\
\hline Villavicencio & 409 & 6,2 \\
\hline Yopal & 321 & 4,9 \\
\hline Neiva & 296 & 4,5 \\
\hline Granada & 160 & 2,4 \\
\hline Medellín & 63 & 0,9 \\
\hline Pereira & 51 & 0,7 \\
\hline Cali & 35 & 0,5 \\
\hline Paz de Ariporo & 7 & 0,1 \\
\hline
\end{tabular}

Fuente: elaboración propia

\section{Dosificación}

Los resultados demuestran que no existe uniformidad de criterio sobre las dosis y posologías de la administración de los péptidos, en la presentación de cápsulas. Sin embargo, el 32,3 \% utiliza entre 150 y 300 mg/día, el 23,5 \% entre 300 y 450 mg/día, siendo esta última la dosis mínima terapéutica recomendada, aunque el 28,2 \% de los evaluadores administra el medicamento según el caso o la patología (tabla 4). Las dosis recomendadas en granulado por 100 mg se ajustan a la posología del fabricante (1 a 2 sobres/día). 
Tabla 4. Posología recomendada por los evaluadores por ciudad para los tratamientos

\begin{tabular}{|c|c|c|c|c|c|}
\hline Ciudad & 1 cápsula* al día & 2 al día & 3 al día & Más de 3 al día & Según el caso \\
\hline Bogotá & 4 & 13 & 16 & 5 & 10 \\
\hline Villavicencio & 3 & 13 & 8 & 1 & 8 \\
\hline Granada & & & 2 & & 1 \\
\hline Paz de Ariporo & & & 1 & & 1 \\
\hline Medellín & 1 & 5 & 1 & & 3 \\
\hline Yopal & 2 & 6 & 2 & & 3 \\
\hline Cali & & 1 & & & \\
\hline Neiva & & 1 & & & 1 \\
\hline Pereira & & 1 & & & \\
\hline Duitama & 5 & 7 & 6 & 1 & 9 \\
\hline Tunja & 4 & 13 & 5 & 1 & 10 \\
\hline Chiquinquirá & 1 & & & & 2 \\
\hline Sogamoso & 3 & 3 & 5 & & 7 \\
\hline Total & 23 & 63 & 46 & 8 & 55 \\
\hline$\%$ & 11,7 & 32,3 & 23,5 & 4,1 & 28,2 \\
\hline
\end{tabular}

*1 cápsula = 150 o 200 mg, según el caso

Fuente: elaboración propia

\section{Tiempo de administración}

El tiempo de observación retrospectivo varió entre los 6 meses anteriores y más de tres años, lo cual ameritó una revisión individual de las historias clínicas. Como resultado el 27,9 \% de los médicos afirmaron utilizar los péptidos desde hace más de tres años, el 24,2 \% dos años y el 34,5 \% por lo menos un año (tabla 5).

Tabla 5. Tiempo de experiencia clínica con el producto

\begin{tabular}{ccccc}
\hline Ciudad & Menos $\mathbf{6}$ meses & $\mathbf{1}$ año & 2 años & Más de 3 años \\
\hline Bogotá & 7 & 16 & 5 & 6 \\
\hline Villavicencio & 6 & 16 & 1 & \\
\hline Granada & 1 & 1 & 1 \\
\hline Paz de Ariporo & & 3 & 3 \\
\hline Medellín & 1 & 3 & 6 & 1 \\
\hline Yopal & & & & \\
\hline
\end{tabular}


(viene)

\begin{tabular}{ccccc}
\hline Ciudad & Menos $\mathbf{6}$ meses & $\mathbf{1}$ año & 2 años & Más de 3 años \\
\hline Cali & & 1 & 1 \\
\hline Neiva & & & 7 & 1 \\
\hline Pereira & 3 & 4 & 6 & 5 \\
\hline Duitama & 1 & 4 & 3 & 10 \\
\hline Tunja & & 3 & 33 & 7 \\
\hline Chiquinquirá & 18 & 47 & 24,2 & 38 \\
\hline Sogamoso & 13,2 & 34,5 & & 27,9 \\
\hline Total & & & 33 \\
\hline \% & & 34 & 2 \\
\hline
\end{tabular}

Fuente: elaboración propia

\section{Efectos colaterales}

En la casuística observada (6.510 pacientes), se reportaron seis incidentes posiblemente relacionados como efecto secundario o colateral del producto. Tres de ellos hacen relación a rash cutáneo leve, dos casos de episodio gastrointestinal (molestia gástrica, vómito) y un caso certificado de eritema nudoso, en un paciente aparentemente sensibilizado a inmunoglobulina G (Duitama, Boyacá). Todos los pacientes evolucionaron satisfactoriamente. En caso de ser aceptados estos episodios como relacionados con idiosincrasia a la proteína porcina o sensibilidad previa a inmunoglobulinas o efecto colateral relacionado con alguno de los excipientes del producto como la lactosa, representarían el 0,09\% de la muestra estudiada.

\section{Patologías observadas}

Las patologías fueron agrupadas en los siguientes grupos: enfermedades bacterianas, enfermedades virales (agudas, crónicas, recidivantes, influenza, herpes I y II, varicela zoster (VZ), VIH-sida; enfermedades autoinmunes (artritis reumatoidea, lupus eritematoso generalizado, síndrome de Sjögren); casos oncológicos (carcinomas, sarcomas, linfomas, anemias aplásicas, hematológicos); atopias respiratorias (hipereactividad bronquial, rinofaringitis); atopias dermatológicas, EPOC, convalecencias (clínicas, quirúrgicas, úlceras tórpidas, fístulas, sobrecarga laboral, alteraciones del ritmo circadiano, retardo pondoestatural); enfermedades degenerativas del SNC (enfermedad de Parkinson, esclerosis múltiple), y otros estados o patologías distintas de las anteriores, entre otras. Los resultados numéricos y porcentuales sobre incidencia de patologías observadas por los evaluadores se pueden evidenciar en la tabla 6. 
Tabla 6. Patologías observadas por los evaluadores por ciudad

\begin{tabular}{ccccccccccc}
\hline Ciudad & $\begin{array}{c}\text { Enf. } \\
\text { bact }\end{array}$ & Enf. vir & Autoin & Oncol & $\begin{array}{c}\text { Enf. deg } \\
\text { SNC }\end{array}$ & $\begin{array}{c}\text { Atopías } \\
\text { resp }\end{array}$ & EPOC & $\begin{array}{c}\text { Atopías } \\
\text { dermatol }\end{array}$ & Convales & Total \\
\hline Bogotá & 175 & 422 & 140 & 255 & 62 & 159 & 85 & 37 & 98 & 1.433 \\
\hline Villavicencio & 71 & 120 & 56 & 36 & 0 & 77 & 8 & 13 & 28 & 409 \\
\hline Granada & 45 & 25 & 44 & 10 & 4 & 12 & 10 & 10 & 160 \\
\hline $\begin{array}{c}\text { Paz de } \\
\text { Ariporo }\end{array}$ & 2 & 3 & 1 & 0 & 1 & 0 & 0 & 0 & 0 & 7 \\
\hline Medellín & 5 & 9 & 5 & 28 & 3 & 10 & 3 & 0 & 0 & 63 \\
\hline Yopal & 12 & 57 & 58 & 16 & 8 & 73 & 29 & 36 & 32 & 321 \\
\hline Cali & 0 & 6 & 4 & 14 & 2 & 2 & 3 & 1 & 3 & 35 \\
\hline Neiva & 22 & 28 & 16 & 2 & 2 & 106 & 100 & 0 & 20 & 296 \\
\hline Pereira & 15 & 10 & 5 & 5 & 5 & 5 & 3 & 3 & 0 & 51 \\
\hline Duitama & 95 & 129 & 388 & 75 & 9 & 93 & 22 & 30 & 15 & 856 \\
\hline Tunja & 264 & 294 & 243 & 89 & 277 & 223 & 43 & 55 & 37 & 1.525 \\
\hline Chiquinquirá & 300 & 200 & 50 & 70 & 0 & 100 & 80 & 30 & 60 & 890 \\
\hline Sogamoso & 90 & 62 & 77 & 48 & 17 & 69 & 24 & 21 & 56 & 464 \\
\hline Total & 1.096 & 1.365 & 1.087 & 648 & 390 & 929 & 410 & 236 & 349 & 6.510 \\
\hline \% & 16,83 & 20,96 & 16,69 & 9,95 & 5,99 & 14,27 & 6,29 & 3,62 & 5,36 & \\
\hline
\end{tabular}

Enf. bact (enfermedades bacterianas), enf. vir (enfermedades virales), autoin (enfermedades autoinmunes), enf. deg. SNC (enfermedades degenerativas del sistema nervioso central), atopías resp (atopías respiratorias), EPOC (enfermedad pulmonar obstructiva crónica), atopías dermatol (atopías dermatológicas), convales (convalescencias).

Fuente: elaboración propia

\section{Apreciación como aporte terapéutico}

El 85,29 \% de los participantes en el estudio expresó su apreciación ético-científica con base en su experiencia propia en la práctica médica, sobre este tipo de terapias suplementarias, y reconoció en estos péptidos alguna característica deseable, útil o ventajosa para su ejercicio, muchas de las ventajas mencionadas estuvieron constituidas por efectos apreciados en la práctica clínica tales como: mejoría clínica de los pacientes, excelente coadyuvante en el manejo de enfermedades que deprimen el sistema inmunológico, sensación de bienestar, respuesta terapéutica a corto plazo, aumento de peso y apoyo nutricional, mejora la respuesta en pacientes con quimioterapia, disminuye las exacerbaciones de algunas patologías, aumenta la energía y vitalidad en algunos pacientes; por mencionar algunos efectos. No hubo objeciones para su uso con fines terapéuticos, rechazo o aprensión hacia los mismos. Sin embargo, 5 evaluadores (3,6 \%) en Bogotá se abstuvieron de dar un concepto, 3 (2,20 \%) en Tunja, $1(0,7 \%)$ en Granada, 8 (5,8 \%) en Villavicencio, 2 (1,4 \%) en Duitama y 1 $(0,7 \%)$ en Sogamoso. Tan solo un evaluador reportó una mala experiencia con el uso del producto en un caso de mielodisplasia. 


\section{Valoración del efecto terapéutico}

Los resultados de la valoración cualitativa por los evaluadores se observan en la figura 2. El promedio en general de la calificación fue de 8.

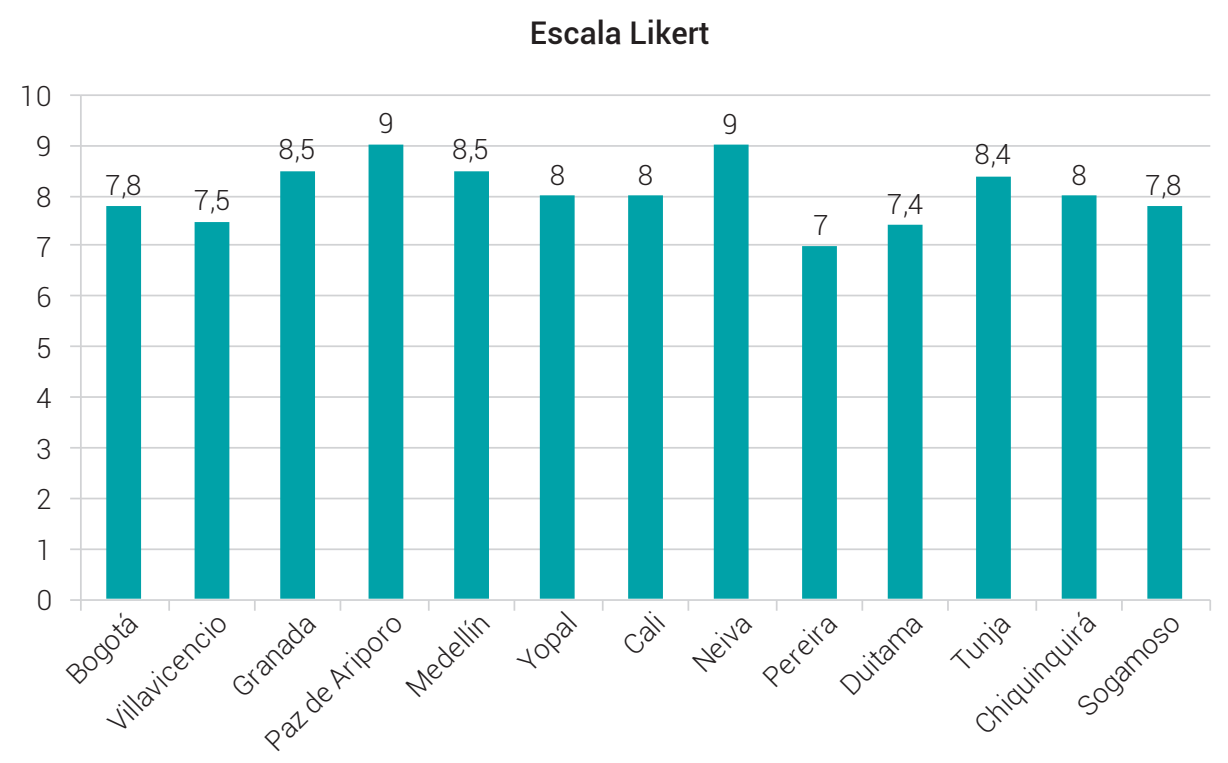

Figura 2. Valoración de los evaluadores sobre el efecto terapéutico Fuente: elaboración propia

La figura 2 nos muestra de manera cuantitativa y cualitativa el "efecto terapéutico suplementario" valorado por la calificación de todos los participantes. En general, el 33,8 \% calificó el producto con valor de 7, el 34,5 \% calificó con 8 y el 26,4 \% con valor de 9. Calificación menor de 6 fue valorada por 5 evaluadores $(3,6 \%)$ y otros dos $(1,4 \%)$ se abstuvieron de calificar en la escala el producto.

\section{Respuestas excepcionales}

El 61 \% de los participantes manifestaron haber observado algunos casos de evolución clínica excepcional o de respuesta terapéutica significativa, los cuales describieron de manera sucinta en el cuestionario o ficha técnica. Estos casos hacen relación a algunas de las siguientes patologías: dengue, VIH-sida, toxoplasmosis, cáncer de diversos tipos y localización (ej.: colon, próstata, tiroides, laringe), enfermedad diarreica crónica, artritis reumatoidea, leucemia, vasculitis del SNC, anemia hemolítica, desnutrición moderada crónica, lupus eritematoso sistémico, retardo pondoestatural, linfoma, asma, anemia aplásica, fibrosis pulmonar idiopática, infección por virus 
del papiloma humano, bronquitis, tuberculosis y micosis asociada a VIH-sida. Es importante anotar que, en este tipo de enfermedades enumeradas, no se suelen ver resultados excepcionales en el ejercicio corriente.

\section{Discusión}

Han et al., en 2014 [44], demuestran que los péptidos hidrolizados de carne de res producidos de proteínas sarcoplasmáticas pueden eliminar radicales libres y algunos iones metálicos, sin embargo, el efecto antioxidante de los péptidos esplénicos de origen porcino aún no ha sido estudiado totalmente. Esta teoría antioxidante concuerda con parte de los resultados expuestos en este estudio debido al efecto benéfico que se evidencia con la prescripción de los polipéptidos linforeticulares, los cuales, al ser extraídos mediante un proceso de fraccionamiento proteico y por los componentes adicionales, tienen un efecto terapéutico y coadyuvante importante. De igual manera, los efectos inmunomoduladores de algunos péptidos han sido evaluados por proliferación de linfocitos, asesino natural (NK), actividad celular, síntesis de anticuerpos y regulación de citocinas. Todos estos compuestos del sistema inmune podrían formar parte del efecto benéfico reportado por los evaluadores de los polipéptidos en este estudio.

Existen otros reportes que demuestran la utilidad de los péptidos como estrategia para el tratamiento de alergias, la disminución de la alergenicidad de preparaciones terapéuticas para el tratamiento de alergias [45]. Similares resultados concuerdan con lo evidenciado en este estudio, en donde varios de los evaluadores reportan el beneficio del uso de este suplemento en enfermedades autoinmunes, cuadros respiratorios alérgicos y atopias dermatológicas, con los polipéptidos linforeticulares.

Los polipéptidos linforeticulares, al ser extraídos por fragmentación proteica del bazo del porcino, conservan las propiedades y celularidad de este, por ejemplo, el bazo contiene un gran número de natural killer T cells (NKT), que detectan antígenos y participan en un amplia gama de respuestas inmunes mediante la secreción de citocinas e induciendo la activación de distintos tipos de células inmunes adaptativas [46] razón por la cual, estos péptidos posiblemente pueden tener diversas acciones en el sistema inmune en las enfermedades que fueron reportadas por los evaluadores de este estudio.

Para ser considerado bioactivo, un componente (o varios) del suplemento dietario, debe generar un efecto biológico medible a nivel fisiológico. Esta bioactividad debe tener el potencial de afectar la salud de manera benéfica, lo cual excluye efectos potencialmente dañinos como toxicidad, alergenicidad, y mutagenicidad [47], lo cual 
concuerda con lo observado en este estudio, en donde se valoró el efecto en salud de 6.510 casos de diversas patologías atendidas por 136 médicos del país, con efectos adversos mínimos.

En 2009, se reportaron cuarenta pacientes con cáncer de estómago, quienes recibieron polipéptidos esplénicos de porcino, el $44 \%$ de los pacientes sobrevivieron al menos 5 años más, comparado con el 11 \% del control, lo cual se traduce en cuatro veces la supervivencia de estos pacientes. Otro dato demuestra en cuarenta pacientes con cáncer de colon con metástasis, el grupo que recibió polipéptidos esplénicos de porcino mejoró significativamente la tasa de supervivencia. Este reporte [48] también sugiere las ventajas de estos compuestos en casos de cáncer de garganta, páncreas y otras patologías, lo cual concuerda con lo reportado en este estudio, donde el 9,9\% (648 casos) de patologías reportadas por los evaluadores son de tipo oncológico.

En términos generales, las terapias alternativas y complementarias han ganado popularidad en varios países en la medida en que se han integrado a los sistemas de salud, utilizando estas terapias unidas a los tratamientos convencionales (medicina integradora). Este tipo de medicina la aplican médicos y sus diferentes aliados en la salud, como fisioterapeutas, enfermeras y psicólogos [49]. Este grupo de profesionales son quienes realizan terapias con polipéptidos linforeticulares en este estudio, con un alto porcentaje de profesionales de la salud con especialidad en medicinas alternativas y complementarias (13\%), el segundo más alto en este estudio. Los médicos holísticos, dedicados a disciplinas no convencionales u ortodoxas (terapias alternativas complementarias -CAM), son quienes parecen tener un mejor conocimiento y documentación sobre este tipo de péptidos y terapias suplementarias, aunque quienes aportaron más cantidad de pacientes por médico al presente estudio fueron los dedicados a la medicina general con un 71,3\%. El enfoque como terapia única o suplementaria se aplicó principalmente en enfermedades en donde los tratamientos corrientes no han dado los beneficios esperados por sí solos, como en patologías agudas y crónicas donde los medicamentos quimo-sintéticos, no han sido de utilidad en todos los casos (enfermedades crónicas de tipo metabólico o autoinmune). Existe una percepción general de todos los encuestados, de que el uso direccionado de estos polipéptidos naturales, podrían significar un aporte útil en el armamentarium terapéutico de la medicina actual. Algunos estudios concuerdan en incluir este tipo de terapias, por ejemplo, contra el cáncer. Existe un estimado que indica que las muertes por esta patología en 2030 aumentarán hasta 11,5 millones de decesos, por lo que es conveniente incorporar péptidos derivados del porcino en las terapias, ya que han demostrado potentes efectos antitumorales inclusive en casos graves de cáncer de hígado [50]. En Colombia, muchos de estos resultados y estudios clínicos 
se encuentran plasmados en el libro de Mejía [51], en donde se evidencian resultados similares realizados en pacientes desde 2002 hasta 2014, los cuales reportan casos similares a los proporcionados en este estudio, en patologías tales como aplasia medular, anemia aplástica idiopática severa y VIH (Linfocitos CD4 y CD8), entre otras.

\section{Conclusiones}

No parece existir una unidad de criterio sobre las dosis y posologías recomendadas para este tipo de péptidos. El promedio por día estuvo en 1 a 2 cápsulas o sobres. A pesar de que dosis mayores a 1 gramo podrían ser aceptadas, las dosis documentadas estuvieron en un 23,5 \% dentro del rango recomendado (300-450 mg/día)

Los polipéptidos linforeticulares también pueden ser utilizados como refuerzo o coadyuvante asociado a estados metabólicos desordenados y defensas orgánicas disminuidas.

Como respuesta al enunciado general de este estudio, y de acuerdo con los datos globales obtenidos en la escala de Likert (rango 1-9), podemos afirmar que la mayoría de los médicos y profesionales de la salud que participaron en el mismo $(94,85 \%)$, reconocieron y calificaron en alto grado (7 a 9) la respuesta terapéutica observada clínicamente con el uso de los polipéptidos linforeticulares (L.M.W).

Se propone el uso de los polipéptidos linforeticulares de manera rutinaria para prevenir y controlar diversas enfermedades de alto costo.

\section{Referencias}

[1] Whyte J, Prather, R. Genetic modifications of pigs for medicine and agriculture. Molecular Reproduction Development. 2011;78(10-11):879-91. doi: https://doi.org/10.1002/mrd.21333

[2] Meurens F, Summerfield A, Nauwynck H, Saif L, Gerdts V. The pig: a model for human infectious diseases. Trends Microbiol. 2012;20(1):50-7. doi: 10.1016/j.tim.2011.11.002

[3] Kuhlmey W. Resultados experimentales y clínicos con el grupo de sustancias CT sobre la enfermedad del cáncer. Revista Española de Oncología, 1953.

[4] Kuhlmey W. Medical treatment of cancer. Medicina. 1954;2(4):205-12.

[5] Kuhlmey W. Krebszell-Auflösung durch ungiftige Glykose-senkung. Arztliche Praxis. 1982;34:1174-78 
[6] Berresem P, Frech S, Hartleb M. Additional therapy with SP 1, improve immune reactivity and quality of life in breast cancer during rehabilitation. Tumor Diagnostic \& Therapy. 1955;6:45-48.

[7] Klose G, Mertens J. Long term results of prospective treatment of carcinoma of the stomach with Polyerga. Therapie Woche. 1977;27:5359-61.

[8] Landgraf G. Cancer therapy in daily practice. Allg Med. 1992;23:764-67.

[9] De Ojeda G, Diez-Orejas R, Portolés P, Ronda M, Del Pozo ML, Feito, MJ, Hartleb, M, Rojo, JM. Polyerga, a biological response modifier enhancing T-lymphocyte-dependent responses. Res Exp Med. 1994;194(1):261-67.

[10] Baier JE, Neumann HA, Taufghi-Chirazi T, Gallati H, Ricken D. Thymopentin, Factor AF2, and SP 1, improve impaired mitogen induced interferon g release of peripheral blood mononuclear cells derived from tumor patients. Tumor Diagnostic \& Therapy. 1994;15:21-26.

[11] Veen A, Ruyter HA, De Mouton JK, Harleb M, Lachmann B. Pretreatment with spleen extracts enhances survival in Influenza A infected mice. Forsch Komplementardem. 1995;3:218-21.

[12] Borghardt JE, Rosein B, Frech S, Harleb M. Polyerga as a supportive therapy could improve quality of life in head and neck cancer patients during chemotherapy. Supportive Care Cancer. 1995;3:360-65.

[13] Vassilev M, Antonov K, Tcheocharov P, Krastev Z. Effects of low molecular weight proteins in chronic hepatitis B. Hepatogastroenterology. 1996;43(10):882-86.

[14] Jurin M, Źarković N, Ilić Z, Borović S, Hartleb M. Porcine peptides decrease the number of experimental lung metastases in mice. Clin Exp Metast. 1996; 14(1):55-60. doi: 10.1007/ BF00157686

[15] Jurin M, Źarković N, Ilić Z, Borović S, Hartleb M. Chemotherapy and spleen peptide preparation SP1, in the treatment of experimental lung metastases of mammary carcinoma in mice. Croatian Medical Journal. 1997;38(4):317-21.

[16] Maar K. Improvement in the general condition of tumor patients. Erfahrungsheilkund. 1998;47:60-64.

[17] Klingmüller M. Spleen peptides activate Natural Killer Cells. Erfahrungsheilkunde. 1999;12:756-59. 

derivados del porcino en el curso clínico de diversas patologías

[18] Borghardt JE, Rosein B, Görtelmeyer R, Lindemann S, Hartleb M, Klingmüller M. Effects of a spleen peptide preparation as supportive therapy in inoperable head and neck cancer patients. Arzeinmittelforschung Drug Research. 2000; 50:178-84. doi: 10.1055/s-0031-1300186

[19] Mejía G. Seguimiento clínico y hematológico de un caso de aplasia medular idiopática con un modificador de la respuesta biológica. Bogotá: C\&D Pharma Scientific Report; 2003.

[20] Moreno MC, Casas C, Villamil Z. Estudio de la composición cualicuantitativa de un compuesto proteico y su estandarización para análisis electroforético. Laboratorios Gamma. Bogotá:Instituto de Referencia Andino, Bogotá. C\&D Pharma Scientific Report; 2003.

[21] Mejía G, Minotta C, Hurtado HJ. Evaluación general sobre los efectos de un nuevo modificador de la respuesta biológica (B.R.M.) en el curso clínico de diversas patologías. Segundo Foro Regional de Investigación Científica. Pereira, Risaralda: Fundación Universitaria del Área Andina. C\&D Pharma Scientific Report; 2003.

[22] Mejía G, De Urbina S. El tratamiento de apoyo metabólico para el cáncer y otras patologías. Bogotá: Reporte Dirección Científica, Prometeus S.A.; 2005.

[23] Mejía G. General considerations on supplementary metabolic intervention in the treatment of human immunodeficiency. Nueva York: C\&D Pharma Scientific Report. Universidad de Brown; 2005.

[24] Mejía G. Aspectos fisiológicos y metabólicos de la respuesta inmune primaria. Bogotá: C\&D Pharma Scientific Report; 2007.

[25] Jiménez CA, Mejía MH, Marulanda C, Torres MA. Valoración preliminar sobre los efectos inmunomoduladores de un suplemento dietario en un grupo de pacientes VIH positivo. Calcará, Quindío: Centro de atención integral del VIH. Hospital de la Misericordia. Bogotá: Informe Dirección Científica. Prometeus S.A; 2008.

[26] Díaz A, Quintero BM, Bastidas Y, Beltrán JF. Adherencia y tolerancia al tratamiento de pacientes con VIH-SIDA en IPS en Casanare. Departamento de Epidemiología. Escuela de Medicina Juan N. Corpas. Bogotá; 2009.

[27] Ardila S, Chaki, J, Martínez. L, Méndez, N, Mejía, G, Soler, et al. Efecto de los polipéptidos linforeticulares en los valores hemáticos en un grupo de caninos sanos en Bogotá, Colombia. Landazuri P, editora. Revista de la Asociación Colombiana de Ciencias Biológicas. Memorias XLV Congreso Nacional de Ciencias Biológicas (ACCB). Armenia-Colombia, 2010 oct. 5-8. p. 63-64. 
[28] Organización Mundial de la Salud (OMS). Estrategia de la OMS sobre Medicina Tradicional 2002-2005. Ginebra: OMS; 2002. 78p.

[29] Decreto 3636 de 2005: por el cual se reglamenta la fabricación, comercialización, envase, rotulado o etiquetado, régimen de registro sanitario, de control de calidad, de vigilancia sanitaria y control sanitario de los productos de uso específico y se dictan otras disposiciones. Diario Oficial No. 46.059, (11 de octubre de 2005).

[30] Kantor E, Rehm, C, Du, M, White, E, Giovannucci, E. Trends in dietary supplement use among US adults from 1999-2012. JAMA. 2016;316(14):1464-74. doi:10.1001/jama.2016.14403

[31] Marsá F. Diccionario de la lengua española usual. Bogotá: Editorial Planeta; 1990. 1506p.

[32] Instituto Nacional de Vigilancia de Medicamentos y Alimentos (INVIMA). Evaluación del proyecto de publicidad de productos competencia de la SMPB. Bogotá: INVIMA; 2011.

[33] Lawrence S. The transfer in humans of delayed skin sensitivity to streptococcal m substance and to tuberculin with disrupted leucocytes. J Clin Invest. 1955; 34(2):219-30. doi: 10.1172/ $\mathrm{JCl} 103075$

[34] Laurence HS, Borkowsky W. A new basis for the immunoregulatory activities of transfer factor. An arcane dialect in the language of cells. Cell Immunol. 1983; 82:102-16. doi: 10.1016/0008-8749(83)90145-4

[35] Laurence HS, Borkowsky W. Transfer factor-current status and future prospects. Biotherapy. 1996;9(1-3):1-5. doi: 10.1007/BF02628649

[36] Levi-Montalcini R. Nervous Growth Factor: Apertura di una nuova frontiera nella neurobiología. Roma-Napoli: Theoria; 1989. 68p.

[37] Levi-Montalcini R. El as en la manga: los dones reservados a la vejez. Barcelona: Critica; 1999. $172 p$.

[38] Levi-Montalcini R. Pensar y vivir a favor de la supervivencia de la especie humana. Barcelona: Península. 2005.

[39] Wilson GB, Paddock, GV. Process of obtaining transfer factor from colostrum, transfer factor so obtained and use thereof. Patente Estados Unidos US4.816.563. 1989. 
[40] Hennen WJ, Lisonbee DT. Methods for obtaining transfer factor from avian sources. Compositions including avian-generated transfer factor and methods of use. Patente Estados Unidos US6.468.534. 2002.

[41] Méndez LM, Peña JA. Manual práctico para el diseño de la escala Likert. España: Trillas; 2007.

[42] Ospina, BE, Sandoval, JJ, Aristizábal, CA, Ramírez, MC. La escala de Likert en la valoración de los conocimientos y las actitudes de los profesionales de enfermería en el cuidado de la salud. Antioquia, 2003. Invest Educ Enferm. 2005;23(1):14-29.

[43] Sánchez F. Psicología social. España: McGraw-Hill. 1998.

[44] Han K, Shimada K, Hayakawa T, Yoon T, Fukushima M. porcine splenic hydrolysate has antioxidant activity in vivo and in vitro. Korean J. Food Sci. An. 2014; 34(3):325-32. doi: 10.5851/ kosfa.2014.34.3.325

[45] Moldaver D, Larche', M. Immunotherapy with peptides. Allergy. 2011;66:784-91. doi: https:// doi.org/10.1111/j.1398-9995.2011.02610.x

[46] Bronte V, Pittet M. The Spleen in local and systemic regulation of immunity. Immunity. 2013;39:806-18. doi: 10.1016/j.immuni.2013.10.010

[47] Sánchez A, Vásquez A. Bioactive peptides: A review. Food Quality Safety. 2017;1(1):29-46. doi: 10.1093/fqs/fyx006

[48] Walker M. Natural cancer remedies that work. DeKalb, Illinois: Publishing and Marketing LLC; 2009. $63 \mathrm{p}$.

[49] Shorofi SA, Arbon, P. Complementary and alternative medicine (CAM) among Australian hospital-based nurses: knowledge, attitude, personal and professional use, reasons for use, CAM referrals, and socio-demographic predictors of CAM users. Complement Ther Clin Pract. 2017; 27:37-45. doi: 10.1016/j.ctcp.2017.03.001

[50] Wu D, Gao Y, Qi Y, Chen L, Ma Y, Li Y. Peptide-based cancer therapy: Opportunity and challenge. Cancer Lett. 2014;351(1):13-22. doi: 10.1016/j.canlet.2014.05.002

[51] Mejía G. Secretos de un Alquimista. Bogotá: Ápice. 2014. 145 p. 